\title{
The Secular Decline in Dental Caries in Children and Its Effect on the Dental Needs of Young Adults
}

\begin{abstract}
In order to establish an efficient means of delivering dental care, every country needs to mesure the prevalence of dental disease. In the United Kingdom, national surveys have been carried out, for both children and adults, since 1968 . During the last 20 years, a decline in the prevalence of dental caries in children has been recorded. This paper considers some of the results of the 1988 Adult Dental Health Survey (published in January 1991) in the light of the secular decline in dental caries in children.
\end{abstract}

\section{INTRODUCTION}

In the 1960 's dental caries was seen as a disease of epidemic proportions affecting the youth of the Western World. In the early 1970's very high DMFS scores were still being reported. For example, Koch and Petersson(1) reported DMFS values of 31.0 and 27.4 for 15 year old children at the start of a 1 year trial of Duraphat fluoride varnish. However, towards the end of the 1970's the view that the dental health of children was improving was rather cautiously being put forward in England by Palmer(2) and others. The theme of a decline in dental caries took on an international flavour when the first international conference devoted to this topic was held in Boston in 1982. Speakers from Denmark, Eire, the Netherlands, New Zealand, Norway, Scotland, Sweden and the United States all confirmed that a downward trend in dental caries in children had occurred.(3) The downward trend was confirmed by a Working Group of the FDI(4) and the World Health Organisation, who had access to figures from the WHO Global Oral Datal Bank.(5)

\section{NATIONAL SURVEYS OF CHILD DENTAL HEALTH}

Relatively small scale epidemiological studies in specific areas provided the first evidence of a secular downward trend in dental caries. Of much greater importance, from a public health point of view, are the results of national surveys, involving a sample large enough and drawn

\author{
J.J. MURRAY \\ Professor and Dean of Dentistry \\ The University Dental School \\ Framlington Place \\ Newcastle Upon Tyne NEZ. 4BW \\ England.
}

A review of national surveys of Child and Adult Dental Health in the United Kingdom.

carefully to reflect the whole population. In 1973 the first survey of Children's Dental Health in England and Wales was carried out.(6)

Twelve thousand children were examined from over 500 schools by a team of seventy dental examiners who had been trained and calibrated. Ten year later the survey was repeated, on a larger scale to include children from Scotland and Northern Ireland.(7) Over 20,000 children were examined in 1983 , by a team of examiners trained to use similar criteria to that employed in 1973 . The results showed that for England and Wales a dramatic reduction in caries had occurred in both primary and permanent dentitions. The DMF of 5 -year-olds had fallen from 4.0 to 1.8; 51 percent of children at this age were now caries free, compared with 29 percent in 1973 . The DMF for 15 year-old children had fallen from 8.4 to 5.6, a decrease of 30 percent. These changes were obviously most welcome, but they become even more important if they represent a permanent change in the amount of caries devastating the dentitions. The possibility that the decline in caries, observed in children, could extend into young adults would be more of major public health significance and would change the perception of both the public and the dental profession with respect to the dental needs of the middle aged and elderly. Children who were 15 in the 1983 Child Dental Health Survey would have been 20 in 1988 when the national survey of Adult Dental Health in the United Kingdom was carried out(8) The results of this 
adult survey, the third to be carried out since 1968 , showed substantial improvements, particularly in the prevalence of edentulousness, which had fallen from 37 percent in 1968 to 29 percent in 1978 to 20 percent in 1988 , taking all adults aged 16 years and over. The survey gave results in 10 year age groups. A perusal of the data for 16-24 year-olds provides the opportunity to determine whether the downward trend in caries, chronicled in the 1970's was apparent in the dental health of young adults at the end of the 1980's.

\section{THE IMPACT OF THE DECLINE IN TOTAL TOOTH LOSS ON THE DENTAL SERVICES}

In the period 1978-1988 the proportion of the adult population with some natural teeth increased by 9 percent in the United Kingdom. The impact of the reduction in total tooth loss was particularly noticeable in the middle aged 35-44, $45-54$ and 55-64 age bands where substantial increases in the proportion of dentate adults was observed (Table 1). Other things being equal, one would expect an increase of the size to stretch existing resources, particularly those devoted to restorative dentistry. However, the net impact on services may be influenced by other factors, such as the decrease in disease among young adults and differences in attendance patterns among older dentate adults.

\section{HOW DO THE YOUNG ADULTS OF 1988 COMPARE WITH OLDEST CHILDREN IN THE 1983 SURVEY WITH RESPECT TO MISSING TEETH?}

In most children's surveys any permanent teeth that are not present in the mouth are categorised as either unerupted, missing due to trauma, missing for orthodontic reasons or missing due to disease. Wisdom teeth are counted as unerupted and the DMF index for children only includes teeth extracted as a result of dental caries.
TABLE 1

Increase in dentate population over the period 1978-1988, by country and age

\begin{tabular}{lccc} 
Country & \multicolumn{3}{c}{ Age } \\
England & $35-44$ & $45-54$ & $55-64$ \\
Wales & $+8 \%$ & $+13 \%$ & $+12 \%$ \\
Scotland & $+17 \%$ & $+27 \%$ & $+21 \%$ \\
Northern Ireland & $+12 \%$ & $+19 \%$ & $+28 \%$ \\
United Kingdom & $+9 \%$ & $+15 \%$ & $+19 \%$
\end{tabular}

TABLE 2

The average number of teeth in each condition comparing 15 -year-olds in 1983 with 16-24-year-olds in 1988

United Kingdom

Condition of Teeth

15-year-olds 16-24-year olds in 1983 (1988)

\begin{tabular}{|c|c|c|}
\hline $\begin{array}{l}\text { Unerupted wisdom teeth } \\
\text { teeth }\end{array}$ & 4.0 & 2.7 missing wisdom \\
\hline Orthodontic loss & & 0.4 missing upper 4 's \\
\hline Traumatic loss & & \\
\hline Congenital loss & $22.4 \quad)$ & \\
\hline Sound and untreated & & 21.2 sound and unt \\
\hline eeth with no decay exp & 2 & 24.3 \\
\hline
\end{tabular}

Decayed or unsound teeth

Filled, otherwise sound teeth

$\begin{array}{ll}0.9 & 0.9 \\ 4.2 & 5.5 \\ 0.5 & \frac{1.3 \_ \text {other missing teeth }}{7.7}\end{array}$

Teeth missing due to decay

Teeth with some decay experience

32.0

32.0

The situation in adult studies is not so simple, particularly with respect to wisdom teeth, which is some cases will still be unerupted, or will have been extracted because of impaction. Thus misinterpretation can arise when comparing the results of older children with young adults because in adult surveys the category of missing teeth includes any tooth not present in the mouth for whatever reason. The 1988 Adult Survey addressed this problem by giving details of missing and unerupted teeth (including wisdom teeth) for young adults. The results ( Table 2), showed that of the 4.4 missing teeth 
among adults aged 16-24 years, 2.7 are accounted for by wisdom teeth which may have been extracted or may still be unerupted. A further 0.4 missing teeth are accounted for by upper first premolars which are likey to have been lost for orthodontic reasons. Thus it is likely that 24.3 teeth amongst $16-24$-year-olds had not experienced decay, compared with 26.4 teeth having no decay experience in 15 -year-olds in 1983 . The mean DMF was 5.6 for 15 -year-olds in 1983 compared with 7.7 for 16-24-year-olds in 1988. The data suggest that the 15 year-olds in 1983 may, on average have had two more teeth that have decayed or have received treatment during the five years since the 1983 survey. The young adults (mean age 20 years) in 1988 are still alm ost 1 DMF tooth better off than 15-year-olds in 1973 .

\section{LOW DISEASE GOALS}

When decay was very prevalent in the community the only way to achieve long term reliance on natural teeth was by way of restorative dentistry. In such times the presence of a large number of filled teeth was an asset and indicated that care and attention had been paid to dental health. With the much lower level of dental caries in the younger generation it is now possible to consider goals related to low disease levels and well as goals related to the restoration of decayed teeth. In the $\Lambda$ dult Dental health Report the proportion of people with 18 or more sound, untreated, teeth was taken as an indication of "low disease". The improvement for 16-24-year-olds (Table 3) who have a considerable number of sound teeth has been dramatic over the last 20 years, (44 percent in 1968, 53 percent in 1978,83 pecent in 1988).

The 16-24-year-olds in 1968, were the 35-44-year-olds in 1988 . The deterioration over time for this indicator of "low disease" has been from 44 percent to 23 percent in 20 years, or approximately 10 percentage points for every ten years. If this rate of deterioration were to be main tained, then in 199875
TABLE 3

The propotion of dentate adults with 18 or more sound and untreated teeth in England and Wales - 1968-1988

\begin{tabular}{llcc}
\hline Age & \multicolumn{2}{l}{$\begin{array}{l}\text { Proportion of dentate adults with } \\
\text { sound (and untreated teeth) }\end{array}$} & \\
\hline & 1968 & 1978 & 1988 \\
$16-24$ & $44 \%$ & $53 \%$ & $83 \%$ \\
$25-34$ & $23 \%$ & $28 \%$ & $42 \%$ \\
$35-44$ & $19 \%$ & $20 \%$ & $23 \%$ \\
\hline
\end{tabular}

TABLE 4

The propotion of dentate adults with 18 or more sound and untreated teeth by social class of the head of household as defined by occupation and age

\begin{tabular}{lcccc} 
Age & \multicolumn{2}{c}{$\begin{array}{c}\text { United Kingdom } \\
\text { Social Class of head of household }\end{array}$} & $\begin{array}{l}\text { All dentate } \\
\text { Adults }\end{array}$ \\
\hline $16-24$ & I, II, IIINM & IIIM & IV,V & \\
$25-34$ & $32 \%$ & $75 \%$ & $80 \%$ & $80 \%$ \\
$35-44$ & $21 \%$ & $43 \%$ & $38 \%$ & $40 \%$ \\
$45-54$ & $11 \%$ & $18 \%$ & $28 \%$ & $21 \%$ \\
$55-64$ & $4 \%$ & $16 \%$ & $14 \%$ & $12 \%$ \\
65 and over & $1 \%$ & $12 \%$ & $26 \%$ & $10 \%$ \\
All ages & $33 \%$ & $4 \%$ & $13 \%$ & $5 \%$ \\
\hline
\end{tabular}

percent of 25-34-year-olds will have 18 or more sound and untreated teeth.

The results shown in the previous section suggest that the dental health of 16-24-year-olds in 1988 will not deteriorate as quickly as in the past. This, in turn, will lead to more positive attitudes to the preservation of teeth in older adults in the future.

\section{EFFECT OF SOCIAL CLASS AND ATTENDANCE AT THE DENTIST}

Previous surveys have shown that those in non-manual occupations have more fillings, but few sound untreated teeth, than those in manual occupations. Two factors may be working together: people from non-manual occupation backgrounds may accept more restorative treatment (rather than 
TABLE 5

The proportion of dentate adults with 18 or more sound and untreated teeth by dental attendance pattern and age

\begin{tabular}{lcccc} 
& \multicolumn{3}{c}{ United Kingdom } & All dentate \\
Age & \multicolumn{2}{c}{ Dental attendance pattern } & Adults \\
\cline { 2 - 5 } & $\begin{array}{l}\text { Regular } \\
\text { Check-up }\end{array}$ & $\begin{array}{l}\text { Occasional } \\
\text { check-up }\end{array}$ & $\begin{array}{c}\text { IIV,V } \\
\text { trouble }\end{array}$ \\
\cline { 2 - 5 } & 79\% & $86 \%$ & $79 \%$ & $80 \%$ \\
$16-24$ & $30 \%$ & $53 \%$ & $47 \%$ & $40 \%$ \\
$25-34$ & $16 \%$ & $23 \%$ & $30 \%$ & $21 \%$ \\
$35-44$ & $10 \%$ & $12 \%$ & $15 \%$ & $12 \%$ \\
$45-54$ & $5 \%$ & $7 \%$ & $17 \%$ & $10 \%$ \\
$55-64$ & $3 \%$ & $5 \%$ & $5 \%$ & $5 \%$ \\
65 and over & $29 \%$ & $49 \%$ & $38 \%$ & $35 \%$ \\
\hline All ages & $29 \%$ & &
\end{tabular}

agree to a clearance and full dentures) and are more likely - to attend for regular check ups, which may result in more detailed diagnosis and early detection of caries. The effect of social class and dental attendance patterns on the proportion of adults with 18 or more sound teeth are shown in Tables 4 and 5, where it can be seen that, taking all age groups, the proportions with this particular indicator of dental health are lowest for Social Class I, II, III N.M and for regular attenders compared with occasional and irregular attenders.

The only age group where this association does not apply is the young adults- the 16-24 year age group. This may indicate that dentists are now adopting a more preventive approach to the management of the young permanent dentition. With the increase in the practice of fissure sealing and sealant restorations, it may well be the proportion with 18 or more sound teeth will increase in the future.

\section{RESTORATIVE TREATMENT (FILLING AND CROWNS)}

The index of 12 or more fill ed teeth was used as a measure of evidence of considerable restorative treatment. In 196832 per cent of 16-24-year-olds had 12 or more filled teeth (Table 6). They moved upwards to 40 percent in 1978 and 49 percent in 1988. Similarly, those aged 16-24 in 1978 moved from 23 percent (with 12 or more filled teeth) to 40 percent in 1988 . However, only 7 percent of 16-24-year-olds in 1988 were in this category.

It will be interesting to see whether the young adults of 1988 can maintain their position in terms of this parameter in ten years time.

\section{THE NEED FOR TREATMENT OF DENTAL CARIES}

Speculating on the possible benefits of prevention and the move away from large numbers of fillings should not blind us to the fact that restorative treatment is still necessary for a large proportion of people. Among dentate adults in the U.K. in 198844 percent had at least one tooth that was decayed or had an unsound filling. The 16-24 year age group had the lowest proportion with decayed or unsound teeth (Table 7).

\section{THE CONDITION OF INDIVIDUAL TEETH AROUND THE MOUTH}

The tremendous change in the dental care of adults in the last ten years can be seen by comparing the conditions of individual teeth for adults aged 16-24 and 25-34 in 1988 (Figs. 1 and 2). The pattern of tooth loss, or untreated 
TABLE 6

The proportion of dentate adults with 12 or more filled teeth by age

\begin{tabular}{llcc}
\hline \multirow{2}{*}{ Age } & \multicolumn{3}{c}{ England and Wales } \\
\cline { 2 - 4 } & $\begin{array}{l}\text { Proportion of dentate adults with } 12 \text { or more filled } \\
\text { teeth }\end{array}$ & 1978 & 1988 \\
\hline $16-24$ & $32 \%$ & $23 \%$ & $7 \%$ \\
$25-34$ & $36 \%$ & $40 \%$ & $40 \%$ \\
$35-44$ & $24 \%$ & $34 \%$ & $49 \%$ \\
$45-54$ & $15 \%$ & $21 \%$ & $41 \%$ \\
55 and over & $9 \%$ & $9 \%$ & $19 \%$ \\
All ages & $25 \%$ & $27 \%$ & $31 \%$ \\
\hline
\end{tabular}

TABLE 7

The components of decayed and unsound teeth by age

United Kingdom

\begin{tabular}{llllllll}
\hline Age & $\begin{array}{l}\text { Some teeth } \\
\text { with } \\
\text { unsound } \\
\text { fillings }\end{array}$ & $\begin{array}{l}\text { Some teeth } \\
\text { filled and } \\
\text { decayed }\end{array}$ & $\begin{array}{l}\text { Some teeth } \\
\text { decayed } \\
\text { not } \\
\text { previously } \\
\text { treated }\end{array}$ & $\begin{array}{l}\text { Some } \\
\text { unrestorable } \\
\text { teeth }\end{array}$ & $\begin{array}{l}\text { Some decay } \\
\text { or unsound } \\
\text { teeth }\end{array}$ & $\begin{array}{l}\text { No decayed } \\
\text { or unsound } \\
\text { teeth }\end{array}$ & Base \\
\hline $16-24$ & $12 \%$ & $15 \%$ & $24 \%$ & $2 \%$ & $38 \%$ & $62 \%$ & 706 \\
\hline $25-34$ & $18 \%$ & $20 \%$ & $21 \%$ & $4 \%$ & $43 \%$ & $57 \%$ & 678 \\
$35-44$ & $21 \%$ & $20 \%$ & $18 \%$ & $5 \%$ & $45 \%$ & $55 \%$ & 619 \\
$45-54$ & $20 \%$ & $25 \%$ & $20 \%$ & $7 \%$ & $50 \%$ & $50 \%$ & 417 \\
$55-64$ & $16 \%$ & $17 \%$ & $22 \%$ & $8 \%$ & $45 \%$ & $55 \%$ & 311 \\
65 and over & $12 \%$ & $16 \%$ & $18 \%$ & $15 \%$ & $47 \%$ & $53 \%$ & 241 \\
All ages & $17 \%$ & $19 \%$ & $21 \%$ & $5 \%$ & $44 \%$ & $56 \%$ & 2971 \\
\hline
\end{tabular}


The distribution of tooth conditions around the mouth for dentate adults in different age groups - 1988,

\section{United Kingdom}

Adults aged 16-24
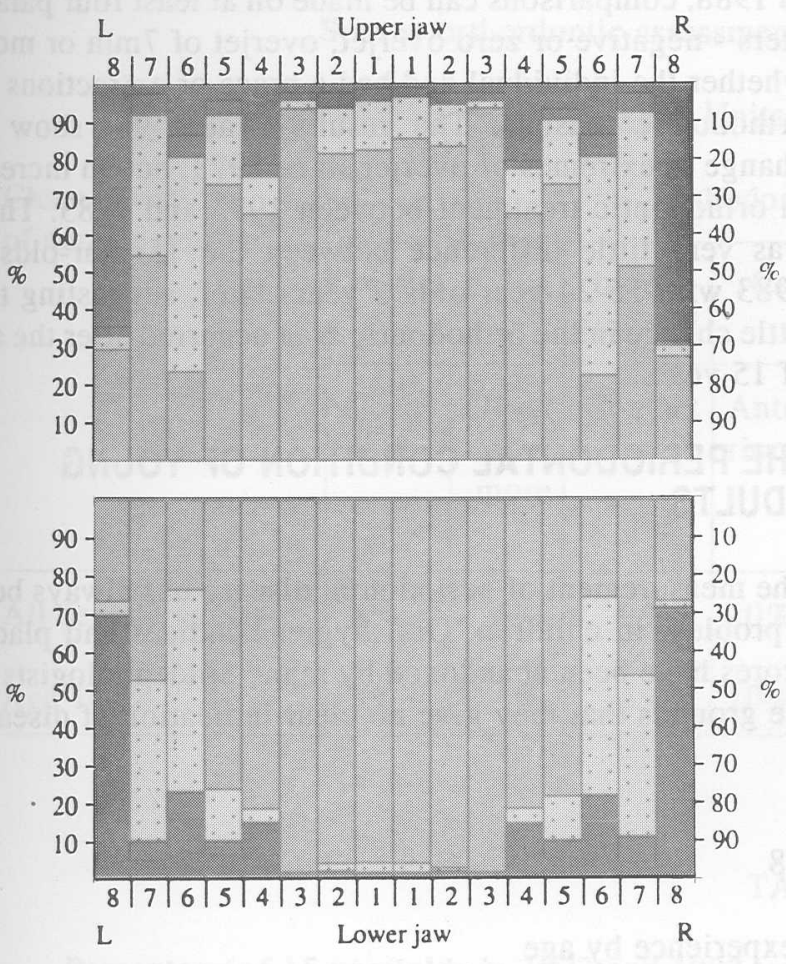

The condition of the natural teeth

Missing

Fig. 1

caries is not very different, but the number of fillings, particularly in molars, premolars and upper canines and incisors is markedly lower for the 16-24-year-olds. These figures also show that, by concentrating on caries prevention in childhood by proper fissure sealing programmes, the number of restorations in molar teeth could be reduced further. Only 25 percent of first permanent molars, and 50 percent of second molars, were sound and untreated by the age of 16-24 years in 1988 .

\section{THE IMPACT OF CHANGES IN DENTAL CONDITIONS OVER TWENTY YEARS}

In 1968 in England and Wales there were 294 million sound and untreated teeth in adults aged 16 years and over; in 1988 the figure was 484 million, an increase of 65 percent. There was also an increase in the number of filled teeth, from 156 million in 1968 to 268 million in 1988, an increase of 72 percent. The number of decayed teeth fell from 50 million to 32 million over the same 20 year period.

If the high average number of sound teeth among young adults aged 16-24 years is retained through later life, and is equalled or surpassed by later generations, the
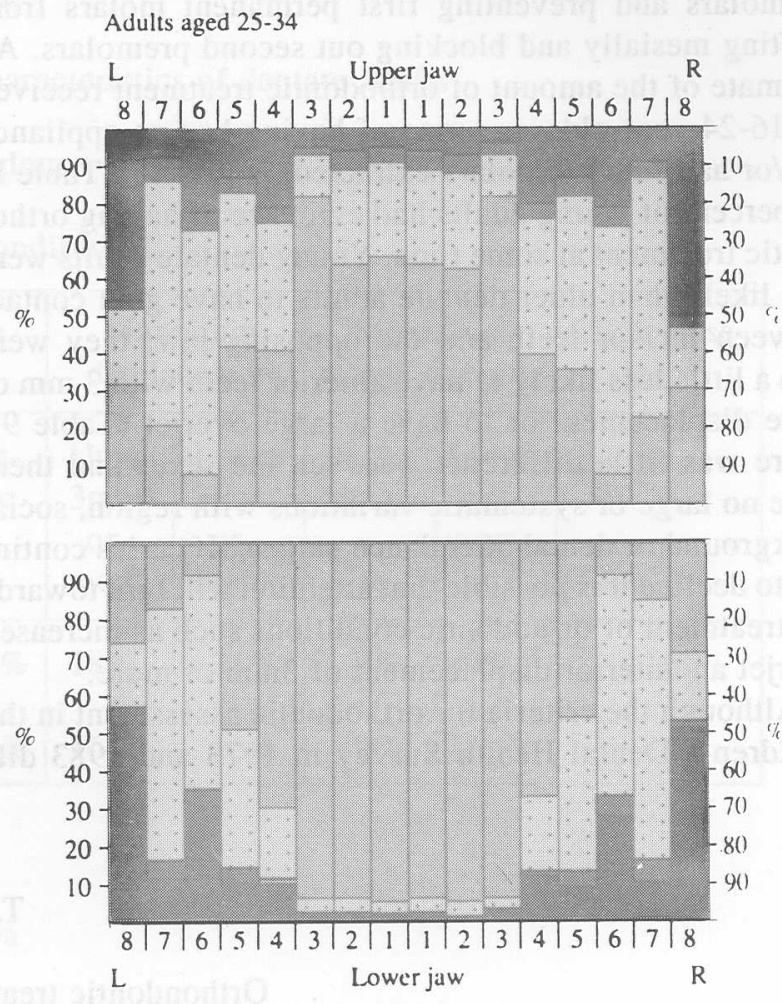

$\begin{array}{llll}\begin{array}{l}\text { Decayed or } \\ \text { unsound }\end{array} & \vdots: \text { Filled } & \begin{array}{l}\text { Sound and } \\ \text { untreated }\end{array}\end{array}$

Fig. 2

population of 268 million filled teeth in 1988 that has increased by 72 percent since 1968 may have reached its peak. This obviously has implications with respect to dental manpower projections.

Over the twenty year period in which the number of teeth in adults increased by 57 percent the number of dentists in the general dental service in England and Wales increased from 10593 to 15869 , an increase of 50 percent. An increasing number of sound teeth going through the various age bands $m$ ay not require a parallel increase in dental manpower.

\section{ORTHODONTIC CONDITION}

The decline in dental caries could have an indirect effect on the need for orthodontic treatment. A high caries experience in children in the past often resulted in the extraction of first permanent molars, which tended to reduce the amount of crowding, especially in the lower arch, albeit at the cost of sometimes producing a deranged buccal occlusion and with residual spacing. The lower levels of caries in the primary dentition means that a much greater proportion of primary molars should exfoliate naturally, thus perserving the space for erupting 
premolars and preventing first permanent molars from drifting mesially and blocking out second premolars. An estimate of the amount of orthodontic treatment received by 16-24-year-olds, in terms of having had an appliance and/or had first premolars extracted, is given in Table 8; 38 percent of young adults had evidence of having orthodontic treatment at some time. Young dentate adults were less likely than older dentate adults to have gum contact between incisor teeth and the opposing jaw; they were also a little less likely to have anterior teeth with $3 \mathrm{~mm}$ or more displacement or to have a large overjet (Table 9). There was little difference between the sexes and there were no large or systematic variations with region, social background or dental attendance pattern. If caries continues to decline it is possible that attention will turn towards the treatment of orthodontic conditions such as increased overjet an anterior displacement of $3 \mathrm{~mm}$ or more.

Although the criteria for orthodontic assessment in the Children's Dental Health Survey in 1973 and 1983 dif- fered from those used in the Adult Dental Health Survey in 1988 , comparisons can be made on at least four parameters - negative or zero overjet, overjet of $7 \mathrm{~mm}$ or more, whether the individual had had a brace or extractions for orthodontic reasons. The results (Table 9a) show no change in extremes of overjet since 1973, but an increase in orthodontic treatment between 1973 and 1983. There was very little difference between the 15 -year-olds in 1983 with 16-24-year-olds 5 years later, suggesting that little change in the orthodontic area occurred after the age of 15 years.

\section{THE PERIODONTAL CONDITION OF YOUNG ADULTS}

The measurement of periodontal disease has always been a problem in children. Oral hygiene indices and plaque scores have been abandoned by many epidemiologists on the grounds that they give no clear indication of disease.

TABLE 8

Orthondontic treatment experience by age

United Kingdom

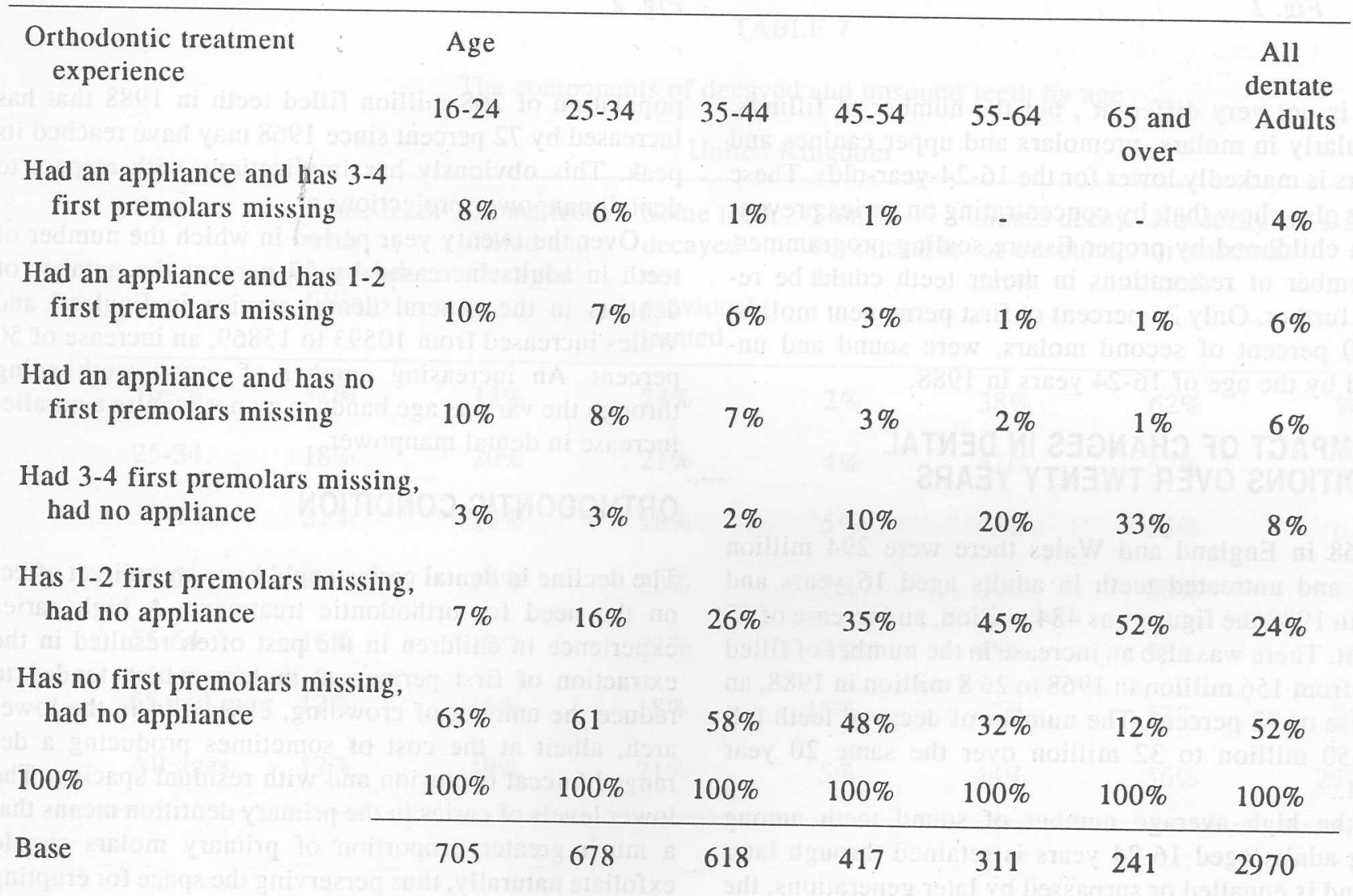




\section{TABLE 9}

Survey orthordontic assessment by characteristics of dentate adults

United Kingdom

\begin{tabular}{|c|c|c|c|c|c|c|c|c|c|c|}
\hline \multirow{3}{*}{$\begin{array}{l}\text { Characteristics } \\
\text { of dentate adults }\end{array}$} & \multicolumn{10}{|c|}{ Orthodontic Condition } \\
\hline & \multicolumn{2}{|c|}{ Overjet } & \multirow{2}{*}{$\begin{array}{r}\text { Inciso- } \\
\text { gingival }\end{array}$} & \multicolumn{2}{|c|}{ Crossbite } & \multicolumn{2}{|c|}{$\begin{array}{c}\text { Maximum } \\
\text { displacement }\end{array}$} & \multicolumn{2}{|c|}{$\begin{array}{c}\text { Maximum } \\
\text { mouth opening }\end{array}$} & \multirow[t]{2}{*}{$\begin{array}{c}\text { Click Base } \\
\text { joint }\end{array}$} \\
\hline & $\begin{array}{l}\text { Nega- } \\
\text { tive }\end{array}$ & $\begin{array}{l}7 \mathrm{~mm} \\
\text { or } \\
\text { more }\end{array}$ & & $\begin{array}{l}\text { Ante- } \\
\text { rior }\end{array}$ & $\begin{array}{l}\text { Post- } \\
\text { erior }\end{array}$ & $\begin{array}{c}\text { Upper } \\
3 \mathrm{mms} \\
\text { or } \\
\text { more }\end{array}$ & $\begin{array}{c}\text { Lower } \\
3 \mathrm{mms} \\
\text { or } \\
\text { more }\end{array}$ & $\begin{array}{l}\text { Under } \\
40 \mathrm{mms}\end{array}$ & $\begin{array}{l}55 \mathrm{mms} \\
\text { or } \\
\text { more }\end{array}$ & \\
\hline All dentate adults & $5 \%$ & $6 \%$ & $9 \%$ & $10 \%$ & $26 \%$ & $18 \%$ & $21 \%$ & $9 \%$ & $20 \%$ & $11 \%$ \\
\hline Age $16-24$ & $3 \%$ & $4 \%$ & $6 \%$ & $10 \%$ & $25 \%$ & $16 \%$ & $16 \%$ & $9 \%$ & $27 \%$ & $8 \%$ \\
\hline
\end{tabular}

TABLE 9a

Percentage of 15 year olds in 1973 and 1983, and 16-24-year-olds in 1988, who had extremes of the overject, orthodontics extractions or had appliance therapy

\begin{tabular}{lcccc}
\cline { 2 - 5 } & $\begin{array}{c}\text { Negative } \\
\text { or Zero }\end{array}$ & $\begin{array}{c}7 \mathrm{~mm} \\
\text { or more }\end{array}$ & $\begin{array}{c}\text { Had a } \\
\text { brace }\end{array}$ & $\begin{array}{c}\text { Had orthodontic } \\
\text { extraction }\end{array}$ \\
\cline { 2 - 5 } 15-year-olds (1973) & 3 & 3 & 17 & 21 \\
15-year-olds (1983) & 5 & 4 & 23 & 29 \\
16-24-year-olds (1988) & 3 & 4 & 28 & 28
\end{tabular}

The measurement of gingivitis has also been difficult, partly because most indices give very high prevalence values in children and doubts have been expressed as to whether the high values for gingivitis have any bearing on the development of destructive periodontal disease in later life. In the 1983 Child Dental Health Survey a WHO periodontal probe was used to measure pocketing and bleeding after probing in 15 -year-old chilren. The results showed that 48 percent of 15 -year-olds in the 1983 Child Dental Health Survey had gingivitis, 33 percent had calculus and 9 percent had mild pocketing (between 3.5$5.5 \mathrm{~mm}$ ). Less than half of one percent of the children had the more severe pocketing.

In the 1988 Adult Dental Health Survey the WHO probe was used to help in the diagnosis of bleeding, calculus and pocketing. The results for 16-24-year-olds in the United Kingdom showed that only 12 percent of 16-24-year-olds were free from periodontal disease as measured in the survey; three quarters showed some bleeding on probing and presence of calculus and one half had evidence of shallow pocketing. Only 2 percent had some deep pockets (Table 10 ). The breakdown by the number of teeth affected gives a better measure of each of these periodontal problems (Table 11). Of the 27.6 standing teeth in the 16-24 years are group (third molars included) 18 were associated with healthy gums, 6 showed evidence of gingivitis and calculus and 2.6 had shallow pockets. From a public health point of view, gingivitis could be reduced by personal oral hygiene, calculus could be removed by regular attendance at the dentist or hygienist. The challenge for the dental profession is how to ensure that the number of shallow pockets does not increase or develop into deep pockets. The situation with respect to increasing age is complicated by the fact that the number of standing teeth falls with increasing age. The percentage of standing teeth affected by shallow and 
TABLE 10

Periodontal condition by characteristics of dentate adults

Characteristics of Propotion of dentate adults with:

Base dentate adults

\begin{tabular}{cccccc|c}
\hline $\begin{array}{l}\text { None of } \\
\text { the porio- bleeding } \\
\text { dontal } \\
\text { conditions }\end{array}$ & $\begin{array}{l}\text { Some } \\
\text { calculus }\end{array}$ & $\begin{array}{l}\text { Some } \\
\text { shallow } \\
\text { pockets }\end{array}$ & $\begin{array}{l}\text { Some } \\
\text { deep } \\
\text { pockets }\end{array}$ & $\begin{array}{l}\text { Some } \\
\text { pocket }\end{array}$ & \\
\hline $\begin{array}{r}5 \% \\
12 \%\end{array}$ & $79 \%$ & $88 \%$ & $69 \%$ & $10 \%$ & $69 \%$ & 2911 \\
\hline
\end{tabular}

TABLE 11

The average number of teeth in each periodontal condition by age

United Kingdom

\begin{tabular}{l|cccccc|c}
\hline $\begin{array}{l}\text { The average number teeth } \\
\text { with the following } \\
\text { condition }\end{array}$ & $16-24$ & $25-34$ & $35-44$ & $45-54$ & $55-64$ & 65 and over & $\begin{array}{c}\text { All dentate } \\
\text { Adults }\end{array}$ \\
\hline Healthy Gums & 17.7 & 14.2 & 12.1 & 9.7 & 7.2 & 5.1 & 12.5 \\
Bleeding - as worst & 5.9 & 6.7 & 6.3 & 5.5 & 4.6 & 3.4 & 5.8 \\
$\quad$ condition & 2.7 & 1.9 & 1.6 & 1.2 & 0.8 & 0.6 & 1.7 \\
Calculus - as worst & 5.5 & 8.5 & 8.7 & 9.3 & 9.0 & 7.4 & 7.9 \\
$\quad$ condition & 4.4 & 6.2 & 6.2 & 6.0 & 6.0 & 4.7 & 5.6 \\
Shallow pockets & 2.6 & 4.5 & 4.9 & 5.0 & 4.4 & 3.6 & 4.1 \\
$\quad$ - as worst condition & 2.6 & 4.4 & 4.7 & 4.8 & 4.2 & 3.3 & 4.0 \\
Deep pockets & - & 0.2 & 0.4 & 0.4 & 0.4 & 0.4 & 0.3 \\
Teeth with exposed roots* & 0.8 & 3.2 & 6.2 & 8.9 & 10.2 & 9.8 & 5.3 \\
\hline Standing teeth & 27.6 & 27.1 & 25.1 & 22.2 & 18.6 & 14.5 & 24.2 \\
Base & 699 & 664 & 604 & 411 & 301 & 233 & 2911
\end{tabular}

*With or without other conditions.

deep pockets shows that from 16 -24-year-olds 9.5 percent of teeth are associated with pocketing, but this increases to 27 percent at 65 years and over. Any measures which slow down the proportion of teeth affected by periodontal pockets, especially deep pockets, would improve the chances of a population remaining dentate for life.

\section{DENTAL EXPERIENCES, ATTITUDES AND BARRIERS TO DENTAL CARE}

During the 1988 Adult Dental Health Survey interview, which was carried out in the homes by a social survey worker, participants were asked if they had various types of dental treatment during their lifetime. The proportion of dentate adults who had experienced twelve different types of dental treatment, for adults of all ages, and for those 16-24 years only, are compared in Table 12, and show that, except for crowns and treatment by a hygienist, young adults have already experienced the twelve commonest forms of dental treatment.

Participants were also asked if they had had a vivid experience at the dentist - "any particular dental experience that stands out in your mem ory as though it hap- 
The proportion of dentate adults who have had different forms of dental treatment by age

United Kingdom

\begin{tabular}{lcc}
\hline Have, at some time, had: & $\begin{array}{l}\text { Age } \\
16-24\end{array}$ & $\begin{array}{c}\text { All dentate } \\
\text { Adults }\end{array}$ \\
\hline Fillings & $91 \%$ & $93 \%$ \\
An x-ray & $74 \%$ & $75 \%$ \\
Extractions & $74 \%$ & $86 \%$ \\
Injection (gum) for & $55 \%$ & $74 \%$ \\
$\quad$ extraction & & \\
Injection (gum) for filling & $80 \%$ & $58 \%$ \\
Gas & $45 \%$ & $58 \%$ \\
A scale and polish & $75 \%$ & $85 \%$ \\
$\quad$ Dentist) & & \\
Treatment from a & $18 \%$ & $24 \%$ \\
$\quad$ Hygienist & & \\
A brace & $28 \%$ & $15 \%$ \\
An abscess & $18 \%$ & $29 \%$ \\
A crown & $15 \%$ & $29 \%$ \\
A bridge & $1 \%$ & $5 \%$ \\
Base & 832 & 3585 \\
\hline
\end{tabular}

pened yesterday?" Fifty percent of dentate adults reported a vivid experience (42 percent in the youngest age group). Again, the answers showed that the proportion of 16-24 year-olds who had experienced pain, extractions, etc. (Table 13) was very similar to that reported by all dentate adults. Ten percent of 16-24-year-olds reported they had had their experience under the age of 10 years, 18 percent between the ages of $10-15$ years and 13 percent were aged 16-24 years. If we are to improve dental attitudes in the future it is essential that we direct attention to avoiding pain, reducing the need for extractions, particularly under general anaesthesia and improving dentists' attitude and behaviour.

In order to try to identify the kinds of hidden barriers which $\mathrm{m}$ ay affect whether or not people go to the dentist, people were asked how strongly they identified with fifteen statements, five were about aspects of fear, five were about dental practice organisation and five related to the cost of treatment. The results (Table 14 ) showed that by the age of 16-24 years most of the barriers were already perceived and the proportions answering the question did not alter substantially in most of the remaining age groups. The dental profession has to respond to these perceived barriers, particularly to those areas which are under the individual dentist's control, in order to improve
Nature of experience by age for dentate who described a vivid dental experience

United Kingdom

\begin{tabular}{lcc}
\hline Nature of experience & $\begin{array}{l}\text { Age } \\
16-24\end{array}$ & $\begin{array}{c}\text { All dentate } \\
\text { Adults }\end{array}$ \\
\hline Pain & $36 \%$ & $30 \%$ \\
Extractions & $25 \%$ & $24 \%$ \\
Problems with treatment & $21 \%$ & $22 \%$ \\
Gas-related & $12 \%$ & $17 \%$ \\
Injections/needles & $19 \%$ & $15 \%$ \\
Dentist attitude/behaviour & $8 \%$ & $11 \%$ \\
Fillings & $12 \%$ & $9 \%$ \\
Blood & $6 \%$ & $6 \%$ \\
Wisdom teeth (incl. & & \\
$\quad$ extraction) & $6 \%$ & $6 \%$ \\
Good/positive experience & $6 \%$ & $6 \%$ \\
Base & 353 & 1794 \\
\hline
\end{tabular}

the attitude of young adults to dental care. The role of the paediatric dentist in formulating a positive approach to dental health in his child patients is just as important for the future well being of the young adult as emphasising the need for preventive dentistry.

\section{IMPLICATIONS FOR THE FUTURE}

The dental health of young adults (16-24-year-olds) is improving. None are edentulous and only 3 percent have a partial denture. In 1988 in England and Wales 83 percent had 18 or more sound teeth ( 37 percent had 24 or more sound teeth). The proportion of this age group with 12 or more filled teeth has fallen from 32 percent to 7 percent in 20 years. If this condition of more sound teeth and fewer filled teeth is maintained the need for the "repair of repair" will diminish as young adults grow older. Greater attention to the prevention of caries in first and second molars in childhood will further decrease the need for restorative treatment in the future.

Although over a quarter (28 percent) of 16-24 year olds said they had worn an orthodontic appliance and a further 10 percent had had 1 or more premolars extracted, presumably to relieve crowding, at least one fifth of this age group had either an overjet of $7 \mathrm{~mm}$ or more or crowding 
TABLE 14

The most important barriers to dental care for dentate adults by age

United Kingdom

The most important barriers to dental care

\begin{tabular}{lc} 
Age & All dentate \\
$16-24$ & Adults \\
\hline
\end{tabular}

No strong association with any barriers $12 \%$

$11 \%$

Fear

I' $\mathrm{m}$ nervous of some kinds of dental treatment

I'd like to be able to drop into the dentist without an appointment

The worst part of going to the dentist is the waiting

I always feel anxious about going to the dentist

If I had toothache I'd rather take pain killers than go to the dentist

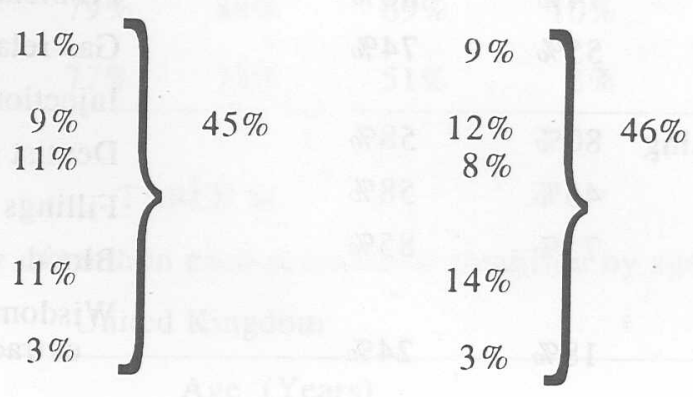

Image of the Dentist (surgery)

I'd like to know more about what the dentist is doing

I don't what fancy (intricate) dental treatment

I don't like lying flat in the dental chair

Dental receptionists are not very helpful or welcoming

Going to the dentist is like being processed on a conveyor belt

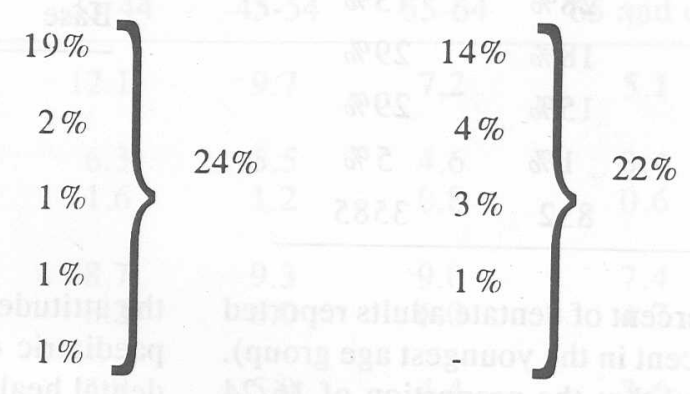

Costs

I would like to be given an estimate without commitment

I find NHS dental treatment expensive

I'd like to be able to pay for my dental treatment by instalments

It will cost me less in the long run if I only go when I have trouble with my teeth

I would like to have more privacy when I am talking to the dental receptionist

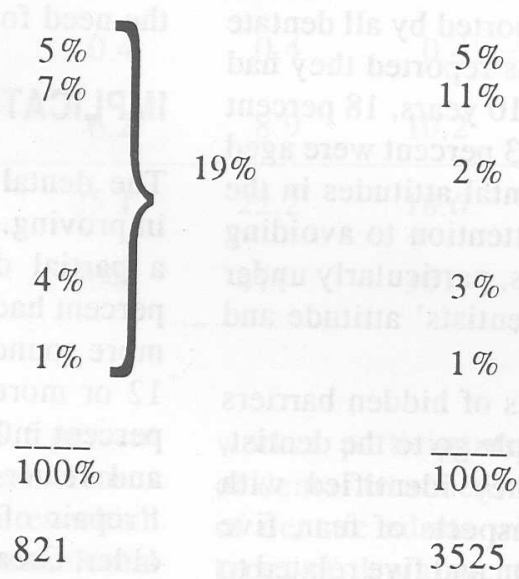

Base 
(maximunder's placement) in the anterior region of $3 \mathrm{~mm}$ or more.

More attention to these conditions in children would improve the dental condition of young adults in the future. The proportion with pocketing (between 3.5 - 5.5 $\mathrm{mm}$ ) showed a sharp increase from 9 percent in 15-yearolds in 1983 to 51 percent for 16-24-year-olds in 1988. Although only 2 percent of young adult had deep pocketing in 1988 , the increased prevalence of shallow pocketing is one aspect of dental health that requires further attention.

Finally, the impact of dentistry on the 16-24-year-olds must not be underestimated. By this age most have experienced a wide range of dental treatment ( 36 percent have had dental pain and 25 percent extractions) and a high proportion have already formulated their attitudes and perceived barriers to dental care. Only 6 percent mentioned having a good or positive dental experience. The interface between the public and the dental profession must be considered urgently if we are to make further improvements in the nations dental health.

\section{References}

1. Peter, L.G. On topical application of fluorides and its inhibiting effect on caries. (1975) Odontol. Revy 26: Suppl. 34.

2. Palmer, J.D. Dental health in children - an improving picture? (1980) Br. dent. J. 149: 48-50.

3. Glass, R.L. (ed). The first international conference on the declining prevalence of dental caries. (1982) J. dent. Res. 61 (spec. iss.), 1301-83.

4. FDI. Changing patterns of oral health, Commission on Oral Health, Research and Epidemiology, (1985) Joint FDI/ WHO Working Group 5, 72nd Annual World Dental Congress, Helsinki, Finland (August 1984).

5. Renson, C.E. Changing patterns of dental caries: a survey of 20 countries. (1986) Ann. Acad. Med. Singapore. 15: 284-98.

6. Todd, J.E.. Children's dental health in England and Wales 1973. (1975) HMSO, London.

7. Todd, J.E. and Dodd, T. Children's dental health in the United Kingdom in 1988. HMSO, London. (1985)

8. Todd, J.E. and Lader, D. Adult dental health 1988, United Kingdom. HMSO, London. (1991) 